\title{
Integration of management systems: A methodology for operational excellence and strategic flexibility
}

\author{
Muhammad Asif • Olaf A. M. Fisscher • \\ Erik Joost de Bruijn • Mark Pagell
}

Received: 18 January 2010/Revised: 15 March 2010/Accepted: 28 May 2010 /Published online: 15 June 2010

(C) The Author(s) 2010. This article is published with open access at Springerlink.com

\begin{abstract}
Organisations employ various management systems (MSs) to systematically address the needs of their stakeholders. As the number of MSs is mushrooming, the need has arisen to integrate them into one holistic business management system that addresses various stakeholder requirements in an integrated manner. However, the dynamics of the integration process are not yet fully understood and research has yet to establish how the integration of MSs gives rise to various types of organisational improvements. This paper focuses on how the integration process unfolds in practice to give rise to a number of socio-technical changes essential to the integration of MSs. This research is based on four cases; it reveals that integration streamlines operational processes through a number of structural, functional, and operational changes. Integration reforms bureaucratic structures, further giving
\end{abstract}

M. Asif $(\bowtie)$

School of Management and Governance, University of Twente, Room No. C-310, Postbus 217,

7500 AE Enschede, The Netherlands

e-mail: m.asif@utwente.nl

O. A. M. Fisscher

School of Management and Governance, University of Twente,

Room No. C-208, Postbus 217,

7500 AE Enschede, The Netherlands

e-mail: o.a.m.fisscher@utwente.nl

\section{E. J. de Bruijn}

School of Management and Governance, University of Twente, Room No. C-306, Postbus 217,

7500 AE Enschede, The Netherlands

e-mail: e.j.debruijn@utwente.nl

\section{Pagell}

Schulich School of Business, York University,

Toronto, Ontario, Canada

e-mail: mpagell@schulich.yorku.ca rise to operational excellence and strategic flexibility. The research also provides the extension of lean production practices bundles, and an operationalisation of Adler's concept of enabling bureaucracy.

Keywords Integration - Management systems ·

Stakeholders · Operational excellence - Strategic flexibility . Enabling bureaucracy

\section{Introduction}

The modern definition of quality extends beyond products/ services specifications to encompass the requirements of a variety of stakeholders. Stakeholder requirements vary from ensuring employees' health and safety, sustainability, customer satisfaction, and transparency in organisational affairs to execution of business processes in a socially responsible manner. To meet stakeholder requirements in a systematic manner, organisations employ certain management systems (MSs) such as quality, environment, health and safety, and social accountability. The International Organisation for Standardisation (ISO) has developed standards for some of these MSs such as ISO 9000 for quality management, ISO 14000 for environmental management, and the ISO 10001, 10002, 10003 series for customer satisfaction complaint systems. These standards are in wide use and are sought by customers (Wilkinson and Dale 2001). The number of these MSs is burgeoning and the need has arisen to integrate them into a single overriding business MS (Karapetrovic 2003; Zutshi and Sohal 2005) for three primary reasons: 1) to ensure that unintegrated MSs do not pull the organisational processes in different directions; 2) to make it easier for organisations to handle various MSs; and 3) to improve organisational 
performance. Further, the literature describing the process of integration of MSs is limited (Karapetrovic 2002; Karapetrovic and Jonker 2003). Future development is warranted because past studies: 1) omit a systematic consideration of the integration process based on empirical data and 2) lack a focus on how integration brings about organisational changes and how organisations can manage the integration process to maximise benefits.

The purpose of this research is to understand the dynamics of integration of MSs as a first step for effective management of integration and its outcomes. It thus focuses on the social, technical, and behavioural changes that accompany integration and lead to operational performance improvement and strategic flexibility. The next section provides a review of literature on the integration of MSs. This is followed by the research design. Individual case description precedes cross-case analysis. The paper concludes with testable propositions.

\section{Integration of management systems}

\subsection{General scheme for integration of MSs}

Integration is carried out to systematically address stakeholder requirements. Integration is a deliberate process of developing a governance structure that makes the management of key stakeholder requirements more systematic. Integration provides an infrastructure for managing and improving along various stakeholder dimensions. Integration can highlight areas which otherwise may remain ignored — such as health and safety and corporate social responsibility. Being part of the main business MS, stakeholder requirements top the management agenda and are mainstreamed. Integration thus discourages suboptimization of some stakeholder requirements in an attempt to satisfy others. The general scheme for integration is shown in Fig. 1, which shows that in contrast to an unintegrated system, an integrated system systematically collects stakeholder demands to design organisational processes accordingly. The outcome is determined through integrated audits; thereafter, integrated continuous improvements are carried out to improve the system.

\subsection{Literature on the integration of MSs}

Since this is theory building research which does not allow a full literature review upfront, the literature review emphasizes publications focusing on MSs, and in particular the integration of MSs. Regarding the MSs, ISO 9000 is the most reported MS in the literature. The later sections of this paper, however, count upon a more disparate literature for enfolding literature (Eisenhardt 1989) and theory triangulation (Miles and Huberman 1994). The available literature on MSs shows that maximum benefits from individual MSs could be obtained when they are integrated into one holistic business MS (Douglas and Glen 2000; Jørgensen et al. 2006; Zutshi and Sohal 2005). The development of one integrated system could also reduce the incompatibilities among individual MSs and minimize the resources required to develop, implement and maintain separate systems (McDonald et al. 2003). Literature on integration of MSs can be divided into three streams.

First stream: This literature addresses basic concepts related to IMS. An IMS is conceptualized as a single set of interconnected processes that share a unique pool of human, informational, material, infrastructure and financial resources in order to achieve a composite of goals related to the satisfaction of a variety of stakeholders (Karapetrovic 2003). Literature in this stream elaborates the concept of integration and provides the basis for more recent IMS literature. Noteworthy works in this stream include Griffith (2000), Karapetrovic (2003), Karapetrovic and Willborn (1998), and Wilkinson and Dale (1999, 2001, 2002).

Second stream: The second stream of literature focuses on further exploration of IMS and in particular on proving the legitimacy of IMS. This research is generally of an empirical nature and mainly comes from case studies and surveys-see, for example, Douglas and Glen (2000), Jørgensen et al. (2006),

Fig. 1 General scheme for integration of MSs

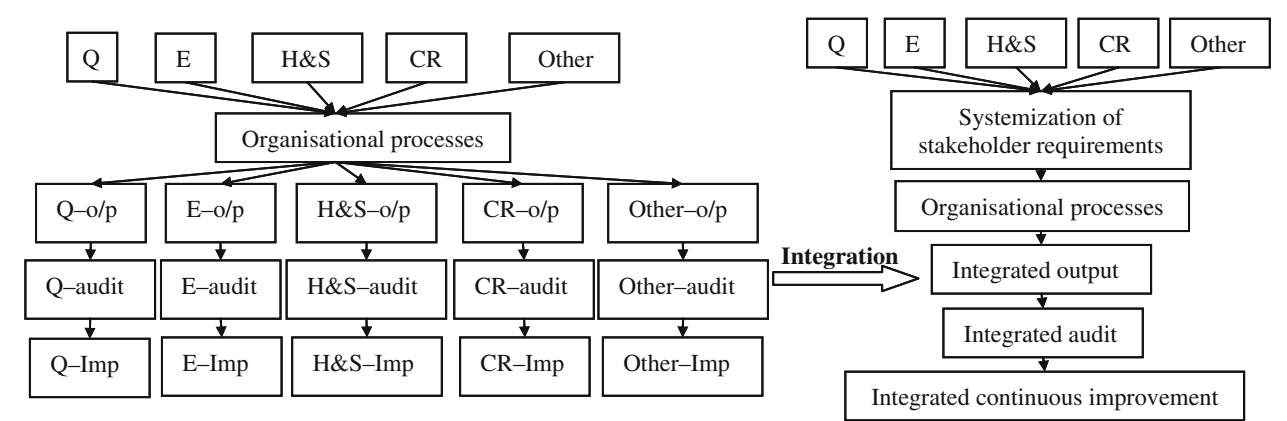

Abbreviations: Q: Quality; E: Environment; H\&S: Health \& safety; CR: Corporate responsibility; Other: other stakeholders' requirements; o/p: output; Imp: Improvement 
Salomone (2008), Zutshi and Sohal (2005). In addition, the second stream literature also focuses on issues, spin-offs, challenges, and factors that influence the integration of MSs. It also reveals a number of strategic, tactical, and operational benefits obtainable from the integration - see, for example, McDonald et al. (2003), Wright (2000), and Zutshi and Sohal (2005). Although this stream focuses on benefits of integration, it does not elaborate the process of integration nor does it provide an understanding of how integration is a precursor of such benefits.

Third stream: This literature focuses on practical approaches to carrying out integration - with a focus on strategies and process of integration, and degree of integration. Examples are Jonker and Karapetrovic (2004), Jørgensen et al. (2006), Karapetrovic (2002), and Rocha et al. (2007). See a summary of the three streams in Table 1.

The three streams of literature have resulted in an enhanced understanding of integration issues. However, the mechanisms of how integration proceeds and how its benefits unfold in practice are not yet fully understood. This is an important point since reaping the benefits from the integration of MSs depends, to some extent, upon how it proceeds in practice. This research explores the process of integration with a particular focus on how integration streamlines the business processes and makes organisations strategically more flexible.

\section{Design of research}

Our objective was to explore what socio-technical changes are accompanied with integration and how integration leads to organisational improvements of various types. It called for data collection from multiple sources of evidence. Case research was thus envisaged to allow for in-depth observation and confidence in findings through the use of multiple data sources and the extraction of the findings through triangulation.

\subsection{Case selection}

We set out to select companies that were 1) front-runners regarding the integration of MSs and were 2) mature in their integration practice. Ahire (1996) noted that a threeyear period is generally considered to be the cut-off point between young and mature organisations. Plants mature in their integration efforts are better able to make a sound cost-benefit assessment of the value of integration. Studying mature organisations also provides greater likelihood of identifying the leading integration practices which could be of greater practical value for other companies. The information regarding "mature and front-runner" organisations was obtained from multiple channels including; a local university's "industry-academia collaboration" database, common consultants, and informal conversation with managers.

With the above selection criteria in mind, we identified seven companies in Pakistan (research sponsor). The industrial sector of Pakistan provided a large population of large-sized manufacturing enterprises operating in a highly competitive environment. Two companies were dropped due to their explicit focus on exploitation (cf. exploration) of already integrated MSs with little focus on the continuous improvement in integration. This information was obtained from conversations with a number of managers at the respective organisations. The remaining five companies articulated the stakeholders' requirements into their systems and carried out integration on a regular basis. Four agreed to participate in the research. A description of the selected organisations is summarized in Table 2.

Table 1 Streams of literature on IMS

\begin{tabular}{|c|c|c|}
\hline Streams in literature & Main topics covered & Supporting literature \\
\hline First stream & $\begin{array}{l}\text { Philosophy, basic concepts, } \\
\text { and ideas regarding integration }\end{array}$ & $\begin{array}{l}\text { Griffith 2000; Karapetrovic 2003; Karapetrovic and Willborn 1998; } \\
\text { Mangelsdorf 1999; Wilkinson and Dale 1999, 2001, 2002; } \\
\text { Winder 2000; Zwetsloot } 1995\end{array}$ \\
\hline Second stream & $\begin{array}{l}\text { Proving legitimacy of an IMS } \\
\text { Spin-offs from an IMS } \\
\text { Challenges faced in integration of MSs } \\
\text { Issues in integration of MSs }\end{array}$ & $\begin{array}{l}\text { Mackau 2003; Matias and Coelho 2002; McDonald et al. 2003; } \\
\text { Oskarsson and Malmborg 2005; Wright 2000; Zutshi and Sohal } 2005\end{array}$ \\
\hline Third stream & $\begin{array}{l}\text { Strategies (and process) of integration } \\
\text { Degree of integration } \\
\text { IMS: a means to sustainable development } \\
\text { IMS: a means to sustainable management } \\
\text { systems }\end{array}$ & $\begin{array}{l}\text { Asif et al. 2009; Beckmerhagen et al. 2003; Bernardo et al. 2008; } \\
\text { Douglas and Glen 2000; Holdsworth 2003; Jonker and } \\
\text { Karapetrovic 2004; Jørgensen 2008; Jørgensen et al. 2006; } \\
\text { Karapetrovic 2002, 2008; Karapetrovic and Jonker 2003; } \\
\text { Labodova 2004; Rocha et al. 2007; Salomone } 2008\end{array}$ \\
\hline
\end{tabular}


Table 2 Characteristics of selected cases

\begin{tabular}{|c|c|c|c|c|}
\hline Characteristics & Pharmaceutical plant & Textile plant & Automobile plant & Dairy plant \\
\hline Main Products & $\begin{array}{l}\text { Solid and liquid } \\
\text { dosage forms }\end{array}$ & $\begin{array}{l}\text { Fabric, yarn, denim, } \\
\text { stitched garments }\end{array}$ & Cars & Dairy products \\
\hline No. of Employees & $>500$ & $>6000$ & $>1000$ & $>500$ \\
\hline $\begin{array}{l}\text { Customers/major } \\
\text { markets }\end{array}$ & $\begin{array}{l}\text { Local, South Asia, } \\
\text { Middle East, } \\
\text { North Africa }\end{array}$ & Europe and USA only & Local & $\begin{array}{l}\text { Middle East, North Africa, } \\
\text { Central Asia, Europe, USA, } \\
\text { and South Asia }\end{array}$ \\
\hline $\begin{array}{l}\text { Management systems } \\
\text { implemented }\end{array}$ & $\begin{array}{l}\text { QMS, EMS, OH\&SMS, } \\
\text { and SA } 8000\end{array}$ & $\begin{array}{l}\text { QMS, EMS, OH\&SMS, } \\
\text { and SA } 8000\end{array}$ & $\begin{array}{l}\text { QMS, EMS, } \\
\text { OH\&SMS, } \\
\text { and SA } 8000\end{array}$ & QMS, EMS, OH\&SMS \\
\hline $\begin{array}{l}\text { Plant specific technical } \\
\text { systems }\end{array}$ & $\begin{array}{l}\text { Good manufacturing/ } \\
\text { distribution practices } \\
\text { (GMP/GDP) }\end{array}$ & $\begin{array}{l}\text { Worldwide responsible } \\
\text { apparel productions } \\
\text { (WRAP) }\end{array}$ & QS 9000 & $\begin{array}{l}\text { Hazard analysis and critical } \\
\text { control point (HACCP) }\end{array}$ \\
\hline
\end{tabular}

The selected cases are large-sized manufacturing companies where issues of quality, environment, health and safety, and social responsibilities are of significant concern and thus are addressed on a high priority basis. These plants are mature in their integration efforts. The mode of production in all cases is make-to-order (MTO). While the system for the management of quality is common in practice, the four cases also employ systems for the management of non-traditional stakeholder requirementssuch as environmental sustainability, employee health and safety, and social responsibility. In addition to these general systems, the four organisations also employ sector-specific systems (Table 2). Thus based on the MSs focusing on both traditional as well as non-traditional stakeholders, this research intends to generalise the integration of MSs.

\subsection{Data collection}

The research used four data sources: 1) in-depth interviews, 2) internal documents and archives, 3) on-site observations, and 4) focus groups discussions. See Appendix A for the interview protocol. The primary source of data comprises the interviews of plant managers, departmental managers, and shop floor employees. Six to ten interviews were conducted in each of the four cases. The explorative nature of this research required a semi-structured approach where the interview protocol allowed flexibility via open-ended questions. Interviewees were asked to briefly describe their firms and operations; their roles and responsibilities; what their firms had done in integration of MSs; and their methodology of integration along with processes, milestones and outcomes.

For a list of the documents and archives consulted for this purpose see Table 3. The internal documents and archives gave evidence of performance metrics before and after the integration of MSs. The on-site observation of daily routines resulted in better understanding of the companies' processes and firsthand information of integrated operations' outcomes. Finally, the trajectory of progression of integration and associated organisational changes were

Table 3 Sources of evidence and the information generated thereof

\begin{tabular}{|c|c|c|}
\hline Source of evidence & Explanation & Purpose \\
\hline Interviews & $6-10$ in-depth interviews in each case & $\begin{array}{l}\text { Primary source of data: to gain in-depth } \\
\text { information about key issues (motivation, } \\
\text { process, and outcomes of integration) }\end{array}$ \\
\hline Internal documents and archives & $\begin{array}{l}\text { Management manual, operating procedures, } \\
\text { work instructions, records, management reviews } \\
\text { reports, minutes of management meetings, audit } \\
\text { reports, corrective and preventive action } \\
\text { reports, performance metrics, technical circulars, } \\
\text { and job descriptions }\end{array}$ & $\begin{array}{l}\text { For triangulation purposes: The internal } \\
\text { documents and archives provided strong } \\
\text { evidence of the managerial actions and } \\
\text { actual situation regarding the integration } \\
\text { of MSs and lean processes }\end{array}$ \\
\hline On-site observation & $\begin{array}{l}\text { Observation of operational activities and informal } \\
\text { conversations with operators }\end{array}$ & $\begin{array}{l}\text { To obtain firsthand information of integrated } \\
\text { processes and lean practices }\end{array}$ \\
\hline $\begin{array}{l}\text { Post-data collection focus group } \\
\text { discussion }\end{array}$ & $\begin{array}{l}\text { A panel of three academicians, one consultant, } \\
\text { and four tactical level managers from four } \\
\text { different organisations all actively involved in } \\
\text { the integration of MSs }\end{array}$ & $\begin{array}{l}\text { Better understanding of how integration } \\
\text { proceeds and is linked with lean operations }\end{array}$ \\
\hline
\end{tabular}


discussed in a post-data collection focus group - a panel of three academicians, one consultant, and four tactical level managers from the four cases of this research (Table 3). A case study protocol was developed to guide the research during the field work.

\subsection{Data analysis}

The data analysis proceeded through within-case analysis for each case followed by cross-case analysis to compare the individual cases, with the aim of developing testable propositions. After data collection and transcription, we coded for the critical steps of the integration process and its outcomes. The coding facilitated the categorisation of data and enabled the development of constructs (Table 5) representing outcomes of integration. This was then followed by the cross-case comparison.

We also took concrete measures to ensure validity and reliability in the research. Construct validity was addressed through data triangulation from multiple sources of evidence, through establishing chains of evidence during data collection, and getting the draft case study reports reviewed by respondents (Yin 2003). Internal validity, which mainly concerns making the right inferences from the data, was ensured using pattern matching and explanation building. We also looked for negative and contrasting evidence that opposed the emerging constructs and relationships to ensure the robustness of our suppositions. Finally, we discussed the emerging patterns (regarding outcomes of integration) with key informants to make sure that correct inferences were being made. Quotes from respondents have been produced where insightful. We also looked actively to enhance the reliability of the research, which means assuring that the operations of case study can be repeated with identical results (Yin 2003). This was carried out through development of the case study protocol. External validity was addressed through selection of multiple cases from different industrial sectors.

\section{Within-case description}

\subsection{Pharmaceutical plant}

This company is a subsidiary of a large European pharmaceutical company and relies mainly on its own patented medicines. It supplies its products to a large number of hospitals locally as well as in countries in South Asia, Middle East, North Africa, and other countries.

The company works in a highly regulated environment where meeting the requirements of regulators is mandatory. There are also pressures from competing foreign subsidiaries and stakeholders such as: employees' union who wanted improved working conditions; shareholders who wanted increased return on their investment; suppliers who wanted reliable forecasts for the raw materials; and distributors who wanted timely supply of medicines to meet varying customer demands. Meanwhile, the company is expected to be a socially responsible business actor due to educated consumers (medical prescribers) who valued management that enacted socially responsible corporate practices. The management decided, proactively, to strengthen its existing technical competencies and also improve the operating system in order to remain a front runner in its commitment to stakeholders. It was decided to mould the work processes in a way that would yield value for the key stakeholders. This was carried out through employing MSs for quality, environment, health and safety, and social responsibility, in addition to good manufacturing / distribution / laboratory practices. Yet management noticed that practicing separate MSs pulled the processes in different directions, gave rise to incompatibilities, and made processes management difficult. The need for integration was realised in favour of one holistic MS.

Integration of MSs started through a number of structural, functional, and operational changes. The separate manuals for quality, environment, and health and safety were merged into one "Operations manual". At the tactical and operational level procedures and work instructions were integrated which, in turn, resulted in the integration in operational activities. The company also integrated the records that were associated with these operations. The integration further enhanced coordination and integration with external stakeholders (e.g., suppliers, customers, and regulators). The company asked its suppliers to provide "strictly scheduled deliveries" since it did not have excessive capacity cushions after the integration. The enhanced integration with suppliers also led the company to streamline its operations where production was driven by market demands. The integration among various functions was, further, facilitated through the use of an advanced ERP system. Other changes in the processes included integration in 1) training sessions - to align the people to an integrated system; 2) auditing - to evaluate and enhance the extent of integration; 3) management reviews - to review the whole system as a means of satisfying stakeholder needs; and 4) continuous improvement-along all dimensions of stakeholders' demands.

Integration introduced a number of behavioural changes which occurred in terms of greater buy-in of the new system and were reflected in enhanced employee motivation which resulted in reduced labour hours and batch manufacturing times despite their enriched jobs. Integration also resulted in reduced waste generation and machine set up time. Integration required management reviews that focused on the whole system and thus provided an 
organisation wide mechanism for continuous improvement. Overall, integration resulted in the development of a lean infrastructure for addressing stakeholder demands. As the production manager summarised,

This is just like killing two birds with one stone: we were interested mainly in the integration... [Later] it dawned to us that integration is the alternate label of lean systems

\subsection{Textile plant}

The textile plant is a large plant (employment size $>6000$, annual denim production capacity $>30$ million linear meters denim) that produces denim, yarn, fabric, and stitched garments. The main customers are European and American companies. While operating in a highly competitive environment, management realised the need to have world class operations. With that in mind, the textile plant spent heavily on the acquisition of advanced machinery to automate operations. However, their competitive edge due to automation eroded as more and more competitors acquired the same machinery.

In the following years, the customer requirements expanded beyond the product specifications to the operations configured around effective management of environment, health and safety of employees and social responsibility. The company employed MSs for quality and environment as immediate measures and later it employed occupational health and safety and social accountability MSs. The company's experience with investment on high tech machines was a learning experience for the management who realised that sustainable advantage required a robust IMS that could steer the business processes in a coherent and integrated manner, while enabling the organisation to simultaneously fulfil the diverse requirements of key stakeholders.

The intent of integration got significant support from key stakeholders, including one customer who offered help in integration. Integration started with redefining business policy - a focus on stakeholder oriented business management through system development rather than acquisition of machines. This was accompanied with extensive structural changes in organisation. Small functional silos such as the quality department and the safety, health and environment (SHE) department were merged into one department with a new name "Systems department". Extensive changes were introduced in the organisational chart to re-structure responsibilities and, likewise, the documentation. The textile plant also took other initiatives to sustain integration, such as total productive maintenance (TPM). The plant also developed stronger ties with customers and suppliers. The management used the textile association to train suppliers about how to preserve cotton and tools to increase its production.

The broad structural changes, in particular the integration in management manuals, procedures, work instructions, checklists, and records helped to reduce the bureaucracy that existed due to isolated functions. Owing to 1) enhanced understanding of jobs by employees; 2 ) integration in different functions that resulted in decreased reliance on specialisation and the breakdown of a hierarchical chain of command; and 3) alignment of employees' behaviour to the new system, the company managed to reduce the bureaucracy due to un-integrated MSs.

Integration accompanied operational performance improvement in numerous areas, including: cycle time reduction, reduction in the number of accidents, waste reduction, better conformance to regulatory control limits, better coordination with regulators, suppliers, and customers, and increase in efficiency and overall effectiveness. Meanwhile, integrated reviews and employees' involvement and development resulted in an infrastructure meant to sustain continuous improvement over time. It also motivated the management to go further ahead in its integration efforts. This was summed up by the plant manager as follows:

[During integration] management was motivated, results were encouraging, and the spirit of change was there; we decided to give it full blow with a simultaneous focus on achieving lean processes

\subsection{Automobile plant}

The automobile plant is a large car manufacturing company that operates in a tough competitive arena with Japanese car manufacturers. It employs MSs for quality, environment, health and safety, and social accountability.

The motivation for integration arose once the company realized that its market share was being snatched away by its competitors. Company management made many efforts to overcome this loss of market share, such as pushing suppliers for cost reductions, and boosting promotion. Such efforts, however, yielded little success, calling for fundamental improvements. Management also struggled with the use of lean production practices. The lean program was initially implemented as a panacea to a problem without understanding the lean philosophy and hence it did not catch root in the organisational setting.

Management then figured out that production related problems cannot be resolved in isolation through the use of best practices. Rather, the company needed to 1) mainstream the lean practices to be more systematic towards cost reduction and 2) mainstream the employed MSs to effectively harness them (as the already employed MSs did 
not seem to be making much difference except adding mandatory accreditation requirements). Management then decided to develop an integrated MS to collect, systemize, and meet the stakeholders' demands in an integrated manner

Integration started with a companywide initiative that relied on teams with members from multiple departments. The general approach towards integration was combining common elements of individual MSs - such as control of routines, non-routines and non-conformances; training sessions; internal audits; control of documentation and data; record keeping; continuous improvement; and issuing of policy statements, etc. The integration proceeded from the company's management manual and then followed the integration in operating procedures and work instructions. The operational activities and records were also redesigned to align with the new integrated procedures. Many concepts of lean production already existed in the plant (without lean philosophy); these ad-hoc practices were re-emphasized.

The automobile plant reaped a number of benefits from the integration. Merging of common elements resulted in the development of a shop floor level "integrated continuous improvement mechanism". Synergy of IMS and (ad-hoc) lean practices resulted in reduction in waste generation, set up time, cost, and enhanced compliance to control limits. Internal documents and archival data revealed that the company experienced a decrease in the number of accidents, rate of non-conformances, and switched to more environmentally friendly manufacturing. The training for integrated execution of activities gave employees $360^{\circ}$ comprehension of the processes, associated risk, and the performance evaluation criteria of their tasks. As the GM production noted,

Lean practices lie in the instinct of [the] automobile sector. Integration re-emphasized the lean practices and led us to take a more assertive approach to the lean production through enhanced internalisation in our routines

\subsection{Dairy plant}

The dairy plant produces a large variety of dairy products for customers both locally and in the Middle East, North Africa, Central Asia, Europe, USA, and South Asia. This company competes with a large number of local and international competitors and endeavours to employ stateof-the-art operations. Becoming certified in quality, environment, and occupational health and safety was an important initiative towards best practices. The need for integration arose as a result of persuasion by consultants and an urge to imitate a competitor who also employed the same practices.
The integration started from linking the common elements in different MSs. Few elements that were unique to a single MS were retained. Individual system manuals were integrated, followed by integration in procedures and work instructions. The operational and supporting activities and records were also redesigned to align with the new integrated procedures. Integration at the dairy plant was carried out as an iterative process rather than a one time activity. It was also accompanied by extensive training sessions.

Among the foremost benefits that the dairy plant achieved after integration was the cost savings from unified external audits. The interviewees noted that documentation reduction was a significant achievement. This is because working in a highly regulated context, documentation is a strict requirement for better traceability of operations. An important outcome, as the production manager noted, was the development of skilled human resources:

Our employees acquired better skills. Integrated working led them to have improved understanding of the processes. This in turn has reduced the number of non-conformances, hazards, and accidents

The technical structures (such as simplified and integrated processes) and social elements (behavioural alignment) also contributed to a reduction in bureaucracy. Management used its skilled employees for "continuous improvement initiatives"-mainly at the operational level. Capitalising on the simplified processes, skilled employees, and continuous improvement initiatives, the company also improved its operational performance in terms of waste reduction, minimization of operational errors, and reduction in workplace injuries. Management, however, perceived integration as a tool for process improvement and integration practices remained dominant at the operational level.

\section{Cross-case analysis}

A general comparison of four cases follows in Table 4 and some examples of constructs that emerged from data analysis are presented in Table 5.

\subsection{The course of integration}

While the focal point of this research is exploring how integration leads to a number of organisational changes, an upfront brief description of some general findings regarding the process of integration in all four cases could provide a rich context required to better understand such changes. In all four cases the individual functions such as the management of quality, environment, and health and safety were integrated into a 


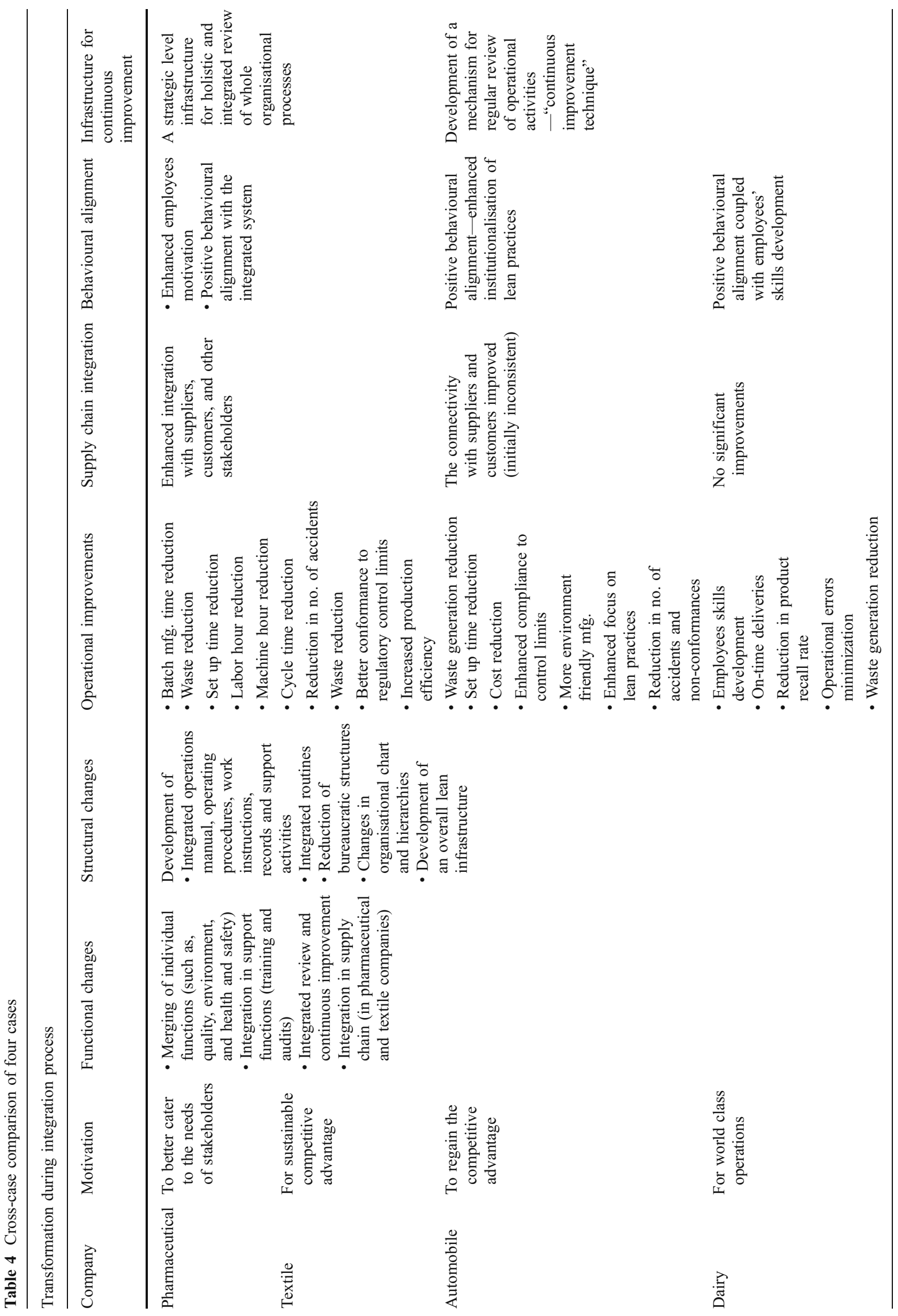


Table 5 Some examples of constructs that emerged from the data representing outcomes of integration

Interview quotes - emerging constructs regarding integration outcomes

Process improvement Documentation Integration • Gone are the days when we used to have piles of documents

- We still have stacks of procedures but in junk store

- Documentation reduction led us to realize that there were many other important things we needed to focus on

Waste reduction

Cycle time reduction

Set up time reduction

Behavioural

alignment

Continuous

improvement

infrastructure

Cost reduction

Performance improvement techniques
- There is much less waste than before

- Waste generation is almost eliminated

- When employees are truly conscious about health and safety and environment, they would do everything astutely to avoid waste reduction because waste may be harmful for them as well

- Now we make product in $25 \%$ less time

- Skilled employees now do it in shorter time than they used to do it before

- Cycle time reduces dramatically after integration

- Operators now switch to new product in seconds

- Employees are so skilled and motivated that it does not take them long to switch to new product

- Integration made employees' work easier and they gained hands-on experience

- We brought safety and convenience to employees work; they obtained skills

- When the operational activities are integrated, employees spend less time in looking for instructions; eventually they feel more comfortable. The integrated handling of various aspects makes employees think and get involved in the job, thus leading to skills development

- Standards require you to review the processes: integration provided a means to review and improve the whole system in an integrated manner

- Integration left behind an infrastructure for continual improvement

- Integrated management reviews and integrated audit is the best means for continuous improvement

- Cost reduction is something everyone had their eyes on

- Cost reduction is the very first outcome of integration

- Cost reductions came from multiple channels

- Cost reduction is something that tempted us to go further ahead

- We used SPC to supplement the direct outcomes of integration

- TPM was employed to sustain the integration
Supporting evidence

Standard operating procedures work instructions

Production record

Production records Inventory records

Machine hours record

Labor hours record

Production reports

Labor hours record showing the time employees spend in execution of a particular activity

Employees training and evaluation records

Management reviews reports, minutes of management meetings, audit reports, corrective and preventive action reports, performance metrics

Production/batch record Company's annual reports

Production record of SPC reports Engineering record of total productive maintenance schedules, past maintenances systems department. This integration changed the hierarchies, responsibilities, and the organisational chart. Integration occurred through a number of changes in governing procedures and processes. Tactical and operational level documentation and the support functions such as procurement, maintenance, general administration, and auditing also underwent integration. Management reviews were also integrated for continuous improvement along various dimensions of stakeholder demands. Integrated training was carried out to facilitate the execution of the new set up and also for integrated auditing. This brought an increased awareness among employees of the reasons for integration, how it would affect their jobs, and how they could benefit from it. 
Integration promoted the use of certain tools to sustain the ongoing integration. The pharmaceutical plant used the ERP system both to facilitate integration and to augment communication with stakeholders. The textile plant initiated the use of TPM and SQC to sustain the ongoing integration. In the automobile plant lean production tools were already in use on an ad-hoc basis; integration reinvigorated their use and put them to more systematic and extensive use.

\subsection{Organisational changes during integration}

\subsubsection{Process improvement}

The purpose of integration at all four plants was to systematically address the stakeholders' demands. The risk with the un-integrated MSs was that they pulled the processes in different directions and led to incompatibilities. Integration aligned the processes to the stakeholders' demands thus reducing the risk of conflicts. The integration resulted in several modifications in the processes - such as reduction in set up time, cycle time, documentation, and waste generation. Overall, integration streamlined the operations. At a more abstract level there was integration in the business steering management manuals followed by integration in the cross-functional procedures and then task specific work instructions and records. The pharmaceutical and dairy plants, in particular, considered integration an important milestone because regulatory requirements demanded them to maintain (hefty) batch records. Employees benefited from integrated procedures and work instructions rather than multiple and sometimes even conflicting documents from various MSs. The integrated procedures were also more user-friendly and easier to develop, maintain, and review. Integration also contributed to the companies' endeavors to reform bureaucratic structures.

\subsubsection{Behavioural alignment}

The management in all four cases realized that employees must accept the idea of integrating MSs before use. Employees' participation was thus promoted through onthe-job training. The textile company noted that the employees' participation further increased as they themselves realised the firsthand benefits of IMS. The automobile company noted that behavioural alignment helped employees to understand and buy the lean practices. The pharmaceutical and dairy plants also noted the development of competent human resources. The resulting behavioural alignment could also be attributed to the simplification of tasks, employees' skills development, and enhanced processes understanding.

\subsubsection{Reforming bureaucratic structures}

The individual MSs bring about formalisation and standardisation as per requirement of standards. Integration provided a means to focus and reflect on such structures. Integration reformed the bureaucratic structures owing to: 1) integration in various functions and resulting in the organisation-wide structural and functional changes that decreased the departmental and employees' isolation, and eliminated the hierarchical chain of command; 2) employees' skills development and behavioural alignment and, thus, less reliance on specialisation; 3) integration in manuals, procedures, checklists, and records, resulting in processes simplification; and 4) a leaner infrastructure to facilitate quicker decision making.

\subsubsection{Continuous improvement infrastructure}

The evidence from interviews as well as internal documents (audit reports, corrective and preventive action reports, management reviews, and minutes of the management reviews) revealed that the four companies targeted continuous improvement, through a focus on: 1) development of integrated management reviews, 2) employee development, 3) involvement of employees in the integration, and 4) involving the employees in the redesign of documents and operations as per requirements of the new system. Although all four companies developed the routines and structures for continual improvement, only the pharmaceutical and textile plants developed the organisation-wide infrastructure for continuous improvement.

\subsubsection{Cost reductions}

Integration of MSs resulted in cost reductions from multiple channels. The savings occurred during unified external auditing, waste reduction, decreased man-hours of internal audits, operational improvements, and effective compliance to regulator's requirements, thus eliminating the possibilities of fines and penalties.

\subsubsection{Supply chain integration and strategic flexibility}

Integration provided the pharmaceutical and textile plants better intimacy with customers and suppliers. The textile plant won the confidence of one main customer to get guidance in integration efforts. In the case of the textile plant, management made efforts to develop and strengthen suppliers' technical capabilities. The pharmaceutical company shared market forecasts with suppliers so that they could forecast supply and could manage their operations accordingly. The focus on the suppliers in terms of enhanced connectivity and supplier development thus remained a central point for the pharmaceutical and textile 
plants. The automobile plant also developed enhanced connectivity with suppliers and customers, which was a problem area of the former un-integrated systems.

Through enhanced connectivity with stakeholders and development of a continuous improvement infrastructure, integration provided the managers an opportunity for environmental scanning and applied decision making. The textile plant, for instance, abandoned the strategy of competing through advanced machinery and shifted its focus to systems development. Improved partnerships with both suppliers and customers, and increased strategic flexibility could be attributed to 1) a change to the "stakeholders-oriented business management" philosophy, 2) enhanced integration with suppliers and customers and redefining business contracts with them; 3 ) the lean infrastructure that facilitates managers' communication with stakeholders; 4) better environmental scanning; and 5) the employees' thoughtful performance and learning mode of organisation.

\subsection{Challenges during integration}

While integration brings about a number of positive organisational changes, this process is not without difficulties and related challenges. A brief description of these challenges provides an informed understanding of how to manage integration for maximum benefits amidst problems. Resistance from the employees was the most important issue at all four plants. This is because integration brought about a number of changes in the way people worked. Additionally, there may have been a fear of losing ownership of the workplace after integration. However, these problems were overcome using extensive trainingan essential aspect of integration in all four cases. Similarly, while the trained internal auditors were readily available for quality and environmental auditing, the four organisations lacked individuals for the evaluation of an integrated system. The inability to evaluate an integrated system also posed difficulty in making continuous improvements. However, over the course of time, the four cases learned to carry out integrated auditing. The textile plant was helped out by one of its customers and the dairy plant by its consultants.

In addition, certain incongruities also emerged during the integration of individual systems. Some aspects of one MS do not fit readily with others. For instance, the aspect identification and significance determination in environmental MSs have nothing to do with quality MSs and thus do not fit easily. The automobile and dairy plants that used the integration approach based on combining the common elements in individual MSs had to retain some elements separately. Secondly, while integration can reduce bureaucracy and help to develop lean processes, managers may also create lengthy procedures and complex work instruc- tions that make the system overly complex. Managers at the Dairy plant faced this problem. Since they perceived documentation to be an important means for operations traceability, the earlier integration efforts tended to generate superfluous documentation, before they finally overcame it after a number of integrated audits and management reviews.

One of the participants in our focus group called this tendency a "state of mind to develop bureaucracy rather than a compulsory requirement". Participants of the focus group also mutually agreed that managers may learn over time when they see the emerging bureaucratic structures counteractive to the desired goals. Focus group participants also noted that there may be a risk of not assigning the right level of importance to individual stakeholder requirements. As a result, requirements of dominant stakeholders (in terms of urgency and power) may be more visible than others. For instance, requirement for quality may catch more attention than the environmental, health and safety, and social accountability requirements. Such problems, however, are highlighted during audits and integrated reviews and thus could be addressed accordingly.

\section{Results}

\subsection{Mechanism of action of integration}

The results reveal that integration brings about radical changes in processes. The focus of integration was activities that were initially broken down into illogical chunks. Such a split of activities might have occurred at the time of design of activities or, subsequently, via gradually adding stakeholders' requirements. As various stakeholders' requirements emerge and then gain salience and/or urgency, managers accordingly accommodate such emerging requirements in existing procedures.

Integration brings about fundamental modifications of a company's functional, structural, and operational nature. All cases reported that various functions and departments were integrated. Integration eliminated the hierarchies of command and control and unified core (i.e. production) and supporting (i.e. audits) procedures and processes. Integration also aligned the employees' behaviour to the operational processes that were more enriched than before integration. The distinguishing feature of this transformation of infrastructure was the requirement for the integrated planning, review, execution, monitoring, control, and communication with stakeholders. Overall, it suppressed physical, structural, and temporal barriers. Such a holistic approach was used not only in the design and execution of processes but also during the review process, thereby ensuring continuous improvement rather 
than a one time activity. This leads to the following proposition:

Proposition 1: Integration of MSs streamlines processes by reducing physical, structural, and temporal barriers.

\subsection{Integration of $\mathrm{MSs}$ - a means for lean production}

Integration started with the intent to systematically address stakeholders' demands; however, it ended with ongoing lean processes. The waste and cost reductions emerge as a strong feature of integration since they were generated from multiple channels, including: 1) cost savings in external audit, accreditation, and waste reduction; 2) time savings through documentation reduction, safe processes, and better management of integrated processes rather than handling of multiple and sometimes conflicting processes; and 3) processes streamlining.

The pharmaceutical and textile companies developed better connectivity with their suppliers and with customers. They were also able to better manage their processes, and the benefits of such improvements were transferred to suppliers in terms of an information system that reduced uncertainties in the receipt of raw material. The savings made by the four organisations - in particular, through waste reduction and integration with suppliers and with customers - are also an essential feature of lean production. All four cases improvised to develop lean processes based on the integration of MSs. Integration thus becomes an alternate path to lean production.

Integration also developed structures and routines to sustain and institutionalise lean processes. This point was conspicuously prominent in the automobile company where integration reinvigorated the use of lean production practices. Integration thus provided an enabling context for the implementation as well as institutionalisation of lean practices.

The institutionalisation of lean programs has become an increasingly important topic of research due to its widespread failures (Browning and Heath 2009; Safayeni et al.1991; Shah and Ward 2003). The reasons for such failures remains a topic of research; however, experience with other performance improvement programs reveals that such programs are often not effectively embedded in organisations (Voss 1995). Integration creates an enabling context for the institutionalisation of lean practices due to: 1) standardisation - a requirement of MSs - that reduces process variations; 2) development of structures (such as integrated procedures and work instructions) that remove variations from a process; 3) development of routines which allow the execution of similar practices over time; and 4) development of social structures (teamwork, behavioural alignment, and regular management reviews to facilitate integration). This leads to the following proposition:

Proposition 2: The integration of MSs gives rise to lean processes and erects the infrastructure to institutionalise lean production practices in the organisational setting - thus preventing lean processes from rolling back after their implementation.

\subsection{Integration of MSs - a means for enabling bureaucracies}

Organisational structures (such as formalised procedures and hierarchical structures) are needed to provide better control of organisational resources and its activities. However, such structures also introduce bureaucracy in the system - a stance underpinned by Max Weber's theory pointing to the need of bureaucratic structures for stabilization, efficiency, and conformance quality. Weber's theory identified bureaucracy as the most rational form of administration; nonetheless, bureaucratic structures also slow down the innovation process and bring rigidity, alienation, and low employee commitment - putting employees in what Weber called an "iron cage".

Managers often struggle to eliminate bureaucratic features such as cutting middle management layers. Yet many such efforts prove to be counterproductive since the layers of middle management are a repository of knowledge. Managers are thus faced with the symmetrical dilemma of bureaucracy as "useful" or "useless". It is suggested that organisations need to develop enabling bureaucracies (Adler 1999; Adler and Borys 1996). At the core of the enabling bureaucracy lies employees' empowerment, using rules and procedures as enabling tools, and hierarchical structures to support the work of the doer rather than to bolster the authority of the higher ups. The integration of MSs is an important means to create enabling bureaucracies through 1) significant reduction in management manuals and governing procedures, 2) integration of various functional silos - bulky middle management layers merged into systems department, 3) integration of processes, 4) promoting employees' development and involvement with less reliance on specialization, and through behavioural alignment, and 5) the development of an overall leaner infrastructure for business processes. Such enabling bureaucracies help the organisation to benefit simultaneously from exploitation of existing capabilities and exploration of future novelties (Adler 1999; Adler and Borys 1996).

Proposition 3: Integration of MSs builds organisational structures that produce "enabling bureaucracies" and thus creates an enabling context for simultaneous exploitation and exploration. 


\subsection{Integration of MSs - a means for strategic flexibility}

Excepting the automobile plant that was already familiar with lean practices to some extent, no other case had the explicit intent of going for lean production. All cases managed to replace bureaucratic structures with enabling infrastructures and developed structures for continuous improvement.

The findings reveal that integration helps in improving customer-supplier relationships and connectivity with stakeholders. After having incorporated the stakeholders' requirements into business processes, managers would communicate to the customers, suppliers, regulators, and shareholders to sustain the continued supply of resources from powerful stakeholders. The resulting external orientation is in line with the institutional theory (DiMaggio and Powell 1983) which states that organisations are dependent on external constituencies (e.g., customers, regulators, and suppliers) for sustainable supply of resources. Organisations conform to the wishes of external constituencies for increased goodwill and legitimation and then communicate such conformance to their stakeholders to ensure the continued flow of needed resources.

The scanning of the environment, determining stakeholder requirements, and then incorporating them into business processes is a dynamic phenomenon. This is because the urgency and legitimacy of stakeholders' requirements and power of stakeholders changes over time (Mitchell et al. 1997), as the business strategy of the textile company changed from high-tech machines to systems development. Integration provides a means and an infrastructure for environment scanning and strategic decision making. Integration thus enhances strategic flexibility and helps companies adapt quickly to the external environment. It motivates the employees, makes jobs simpler, and facilitates more involved performance. This puts the organisation in a learning mode.

Proposition 4: Integration enhances external orientation and leads to greater strategic flexibility.

\section{Discussion}

The research reveals that integration brings about fundamental improvements in processes through suppressing physical, structural, and temporal barriers. This in turn decreases the departmental isolation and links the essential components of a system that were previously treated as isolated chunks. The breakdown of activities creates problems. Namely, at the micro level this appears in the inability of the operator to understand the work process and thus inability to make even minor adjustments in equip- ment. Such tasks are reserved for specialists. On a macro level it interferes with the completion of the overall task in the best possible way (Pasmore 1988).

The findings of this research are in line with the "sociotechnical system theory" which suggests that an organisation has two sub-systems (technical and social). How well the social and technical sub-systems are designed with respect to one another and with respect to the demands of the external environment determines organisational effectiveness (Pasmore 1988). The findings of research are also in line with the "systems theory" which views a system as a "composite of inter-linked processes that function harmoniously, share the same human, material, information, infrastructure and financial resources, and are all directed towards the achievement of set goals" (Jonker and Karapetrovic 2004, p. 612).

7.1 Integration - a methodology for operational excellence and strategic flexibility

Among the organisational changes accompanied by integration, development of lean processes is the most important. The savings in resources from multiple channels give rise to sustainable competitive advantage. Our findings are in line with the resource-based theory which states that organisations need to develop heterogeneous resources to gain a sustainable competitive advantage (Barney 1991; Wernerfelt 1984). Research also highlights how lean practices could be institutionalised in an organisational setting. Integration provides both the social and technical structures and routines that are necessary for sustaining lean processes. Our findings are also consistent with Shah and Ward (2003) who found that organisations develop sets of routines (manufacturing practices) over a period of time and these practices change infrequently.

This research contributes to the theory and practice of lean production in two ways. First, lean production is shown to consist of a bundle of practices (Browning and Heath 2009; Shah and Ward 2003); research has yet to focus on the integration of MSs among these bundles. One of the possible reasons may be that integration of MSs is still a developing topic (Asif et al. 2009; Karapetrovic and Jonker 2003). To our knowledge this is the first research to extend the subsets of lean practices through inclusion of integration of MSs in the lean bundles. Second, with a simultaneous need for the integration of MSs and the need for lean production, this research provides the required channel-the proposed channel is different from conventional options which focus solely on the technical aspects (employing tools and techniques of lean production or of quality management) without considering the stakeholders. The strength of this approach lies in providing additionally greater opportunities for environmental scanning and 
making strategies accordingly. Integration promotes learning and allows adapting to the external environment with agility, thus providing necessary strategic flexibility.

\subsection{Integration of MSs - a tool to reform bureaucracy}

The (standardised) MSs build on the dictum "say what you do, and do what you say" and as such promote formalisation and bring about rigidity in the system. The resulting bureaucracy hampers innovation (exploration) although it may facilitate exploitation (Benner and Tushman 2003). Dealing with such hampering bureaucratic structures has always been a challenge for managers. Managers are always looking for the means to overcome the adverse impacts of bureaucracy - for instance, through the use of information technology (IT) (Colurcio 2009) but with little success (Jain 2004). The pivotal research of Adler (1999) and Adler and Borys (1996) calls for the need to nurture "enabling bureaucracies" but how to create such enabling bureaucracies remains a question. The process of integration, in particular, the modification of socio-technical structures delineated in this research provides a means for developing enabling bureaucratic structures.

To conclude, future research should focus on whether these results replicate in other settings. Future research also needs to focus on the convergent validity of lean practices-how different versions of lean (with various subset practices) share a common set of assumptions and prescriptions.

Open Access This article is distributed under the terms of the Creative Commons Attribution Noncommercial License which permits any noncommercial use, distribution, and reproduction in any medium, provided the original author(s) and source are credited.

\section{Appendix A. Interview protocol}

\section{General company information}

Plant employment?

Plant sales-last 3 years?

Products made at plant?

Single/multiple plants?

IMS is in practice since?

\section{Motivation for integration of MSs}

What type of MSs, organisation employs (especially regarding the management of quality, sustainability, health and safety, social responsibility, etc.)?

What is the role of IMS in the overall management system of organisation?

What is your motivation for integration of MSs? Did any stakeholder demand this MS?

What do you think is the most important factor in the decision to carry out integration of MSs?
What are the imperatives/essential features of this IMS?

Process and outcomes of integration of MSs

How the integration of MSs proceeds and affects the operations?

What changes take place sequentially during integration?

What types of operational improvements have resulted (if any)?

How the integration results in these operational performance improvements?

What types of savings resulted after integration of MSs? Could you please give a few examples?

What is the impact of IMS on waste generation?

How the integration affected the relationship with stakeholders? with suppliers, customers, regulators, and others?

What type of supplier practices prevail in organisation (in terms of selection, development, evaluation, and feedback)?

What is the impact of integration on the customers and customer-related aspects (customer satisfaction and market image)?

How integration affects the productivity, efficiency, cycle time, setup time, and other performance metrics used in your organisation?

What is the role of employees in an IMS (in terms of involvement, behavioural changes, problem solving, and cross-functional participation)?

How do you manage the product flow? What options are commonly used for this purpose (in terms of JIT, kanban or pull production, production smoothing, quality improvement, and employee involvement)?

What type of improvement strategies are used in organisation? What about quality circles, SPC and TPM?

\section{References}

Adler PS (1999) Building better bureaucracies. Acad Manage Exec 13:36-47

Adler PS, Borys B (1996) Two types of bureaucracies: enabling and coercive. Adm Sci Q 41:61-89

Ahire SL (1996) TQM age versus quality: an empirical investigation. Prod Invent Manage J 37:18-23

Asif M, Bruijn EJD, Fisscher OAM, Searcy C, Steenhuis HJ (2009) Process embedded design of integrated management systems. Int J Qual Reliab Manage 26:261-282

Barney J (1991) Firm resources and sustained competitive advantage. J Manage 17:99-120

Beckmerhagen IA, Berg HP, Karapetrovic SV, Willborn WO (2003) Integration of management systems: focus on safety in the nuclear industry. Int J Qual Reliab Manage 20:210-228

Benner MJ, Tushman ML (2003) Exploitation, exploration, and process management: the productivity dilemma revisited. Acad Manage Rev 28:238-256

Bernardo M, Casadesus M, Karapetrovic S, Heras I (2008) Management systems: integration degrees. Empirical study. Paper presented at the 11th Quality Management and Organizational Development (QMOD) Conference, Linköping, Sweden 
Browning TR, Heath RD (2009) Reconceptualizing the effects of lean on production costs with evidence from the F-22 program. J Oper Manag 27:23-44

Colurcio M (2009) TQM: a knowledge enabler? The TQM Journal 21:236-248

DiMaggio PJ, Powell WW (1983) The iron cage revisited: institutional isomorphism and collective rationality in organizational fields. Am Sociol Rev 48:147-160

Douglas A, Glen D (2000) Integrated management systems in small and medium enterprises. Total Qual Manag 11:686-690

Eisenhardt KM (1989) Building theories from cases study research. Acad Manage Rev 14:532-548

Griffith A (2000) Integrated management systems: a single management system for project control? Eng Construct Architect Manag $7: 232-240$

Holdsworth R (2003) Practical applications approach to design, development and implementation of an integrated management system. J Hazard Mater 104:193-205

Jain A (2004) Using the lens of Max Weber's theory of bureaucracy to examine E-Government research. Paper presented at the 37th Hawaii International conference on system sciences, Hawaii, USA

Jonker J, Karapetrovic S (2004) Systems thinking for integration of management systems. Bus Process Manag J 10:608-615

Jørgensen TH (2008) Towards more sustainable management systems: through life cycle management and integration. J Clean Prod 16:1071-1080

Jørgensen TH, Remmen A, Mellado MD (2006) Integrated management systems-three different levels of integration. J Clean Prod $14: 713-722$

Karapetrovic S (2002) Strategies for the integration of management systems and standards. The TQM Magazine 14:61-67

Karapetrovic S (2003) Musings on integrated management systems. Meas Bus Excell 7:4-13

Karapetrovic S (2008) Integrative augmentation of standardized systems. Paper presented at the 12th ICIT conference, Taiwan

Karapetrovic S, Jonker J (2003) Integration of standardized management systems: searching for a recipe and ingredients. Total Qual Manag 14:451-459

Karapetrovic S, Willborn W (1998) Integration of quality and environmental management systems. The TQM Magazine 10:204-213

Labodova A (2004) Implementing integrated management systems using a risk analysis based approach. J Clean Prod 12:571-580

Mackau D (2003) SME Integrated management system: a proposed experiences model. The TQM Magazine 15:43-51

Mangelsdorf D (1999) Evolution from quality management to an integrative management system based on TQM and its impact on the profession of quality managers in industry. The TQM Magazine 11:419-425

Matias JCDO, Coelho DA (2002) The integration of the standards systems of quality management, environmental management and occupational health and safety management. Int J Prod Res 40:3857-3866

McDonald M, Mors TA, Phillips A (2003) Management system integration: can it be done? Qual Prog 36:67-74

Miles MB, Huberman AM (1994) Qualitative data analysis: an expanded sourcebook. Sage, Thousand Oaks

Mitchell RK, Agle BR, Wood DJ (1997) Towards a theory of stakholder identificaion and salience: defining the principle of who and what really counts. Acad Manage Rev 22:853886

Oskarsson K, Malmborg FV (2005) Integrated management systems as a corporate response to sustainable development. Corp Soc Responsib Environ 12:121-128

Pasmore WA (1988) Designing effective organizations: the sociotechnical systems perspective. Wiley, New York

Rocha M, Searcy C, Karapetrovic S (2007) Integrating sustainable development into existing management systems. Total Qual Manag Bus Excel 18:83-92

Safayeni F, Purdy L, Engelen RV, Pal S (1991) Difficulties in just-intime implementation: a classification scheme. Int J Oper Prod Manag 11:27-36

Salomone R (2008) Integrated management systems: experiences in Italian organizations. J Clean Prod 16:1786-1806

Shah R, Ward PT (2003) Lean manufacturing: context, practice bundles, and performance. J Oper Manag 21:129-149

Voss CA (1995) Alternative paradigms for manufacturing strategy. Int J Oper Prod Manage 15:5-16

Wernerfelt B (1984) A resource-based view of the firm. Strateg Manage J 5:171-180

Wilkinson G, Dale BG (1999) Integrated management systems: an examination of the concept and theory. The TQM Magazine 11:95-104

Wilkinson G, Dale BG (2001) Integrated management system: a model based on total quality approach. Manag Serv Qual $11: 318-330$

Wilkinson G, Dale BG (2002) An examination of the ISO 9001:2000 standard and its influence on the integration of management systems. Prod Plan Control 13:284-297

Winder C (2000) Integrating OHS, environmental and quality management standards. Qual Assur 8:105-135

Wright T (2000) IMS - three into one will go!: the advantages of a single integrated quality, health and safety, and environmental management system. Qual Assur J 04:137-142

Yin RK (2003) Case study research: design and methods. Sage, Thousand Oaks

Zutshi A, Sohal AS (2005) Integrated management system: the experiences of three Australian organisations. J Manuf Tech Manag 16:211-232

Zwetsloot GIJM (1995) Improving cleaner production by integration into the management of quality, environment, and working conditions. J Clean Prod 03:61-66 